\title{
An Investigation into Chafe's Six Semantic Configurations Through the Poem "Echo" by Christina Rossetti
}

\author{
Luu Quy Khuong', Tran Tin Nghi \\ ${ }^{1}$ Department of International Studies, University of Foreign Language Studies - the University of Da Nang, Da Namg, Viet Nam \\ ${ }^{2}$ Foreign Languages Center, Ho Chi Minh City University of Food Industry, Ho Chi Minh City, Viet Nam
}

Email address:

lqkhuong@ufl.udn.vn (L. Q. Khuong), nghitt@entp.edu.vn (T. T. Nghi)

\section{To cite this article:}

Luu Quy Khuong, Tran Tin Nghi. An Investigation into Chafe's Six Semantic Configurations Through the Poem "Echo" by Christina Rossetti. International Journal of Language and Linguistics. Vol. 6, No. 2, 2018, pp. 31-35. doi: 10.11648/j.ij11.20180602.11

Received: February 19, 2018; Accepted: March 5, 2018; Published: March 23, 2018

\begin{abstract}
Chafe (1970) first introduces the theory of the linguistic structures as the generative-transformation type and illustrated these structures basing on the 'verbs' of all sentences. In his theory, the verb plays an important role in determining the organizations of all sentences. In his book, Meaning and the structure of language, Chafe defines 'four main heads' that any languages follow naturally such as semantic configurations, the post-semantic processes, symbolization and phonological structures. In this paper, the authors only focus on the analysis of the semantic configurations proposed by Chafe (1970) and test how the rules work with the poem "Echo" written by Christina Rossetti [7] in order to help the readers to better understanding the poem in the light of semantic structures. Rossetti $(1830-1894)$ is a well-known English poet with many masterpieces of romantic, devotional, and children's poems. "Goblin Market and "Remember" are two of her famous publications. The purpose of choosing "Echo" because this is a success of Christina Rossetti's poetry. Normally an echo is believed not as a good concept for poetic purposes. However, with her deeply emotional and sentimental use of metaphor this poem is touching the hearts of all people by a variety of complex semantic configurations. The authors use the Chafe's theory to investigate the effects of semantic configurations and evaluate them through the analysis of Echo.
\end{abstract}

Keywords: Semantic Configurations, Meaning, Structures, Post-Semantic Processes, Symbolization

\section{Introduction}

By the year 1960s, languages were viewed in the light of the structuralism leading by Ferdinand de Saussure and syntactic structures introduced by Noam Chomsky. Chafe [2] viewed languages based on the theory of 'semantic features' and contrast it to the two former linguistic schools. A signifier is considered as the sound pattern of a word while a signified is treated as the concept or meaning of the word [4]. Structural linguists put meaning into sentences and sentences are formed by the structures, and phonology in turn puts the words or sentences into the sounds. The semantic structures were not much paid attention enough, so that linguistics fails to interpret for these well-known literature works that violated the syntactic rules, but they did perform the linguistic functions like "Echo" poem written by Christina Rossetti. It was necessary that we had to take 'semantic structures' and 'conceptual structure' into accounts in analyzing the literature works. These two terms at first used to be treated as one kind of thing. Thanks to Chafe's book, Meaning and Structure of Language, we can distinguish two of the terms clearly and basically. That is also the reason why the structure of English semantics is getting more and more interested with many topical issues nowadays. In this paper, we examines the overall semantic structures, and their configurations suggested by Chafe to explain why some of poems even break the grammatical rules, but they are both 'looked' and 'sounded' structurally through Echo poem written by Christina Rossetti [7]. From this research, we can apply Chafe's theory in studying and teaching poems via semantic structrutes and configurations to help the learners see how meaning of words is conveyed by their own semantic structrures and how they are configed with each others to create 'figures of speech', espcially in the literature work. 


\section{Literature Review}

One approach [10] proposes the models of word recognition basing on the effects of sentence-level semantic context to which they belong. His research has considered 'the availability of lexical entries as a function of stimulus information and contextual constraint' (p.25). The result is reported that sentence-level contexts hardly preselect a set of suitably contextual words until the spoken information is available. Therefore, contextually effects are only activated when lexical access of the words is produced.

Sajin and Connine [8] covers the role of semantic representations in recognizing spoken words [8]. They report that high-number-features words will influence lexical decision reaction times in that semantically high-numberfeature words are processed faster than low-number-feature ones. In other word, semantic representations directly affect the recognition of 'the spoken words', and enhance suboptimal listening conditions (e.g., background babble).

Anderson, Chiu, Huette, \& Spivey [1] suggests that 'language and vision interact immediately in non-trivial ways', though the exact procedures of this interaction is not clear enough [1]. They do conclude that not only linguistic information influences visual perception, but visual information also affects language comprehension in real-time in some other ways.

According to Challis [3], Rossetti wrote seven poems about infant death. One of very extraordinary things was that Rossetti did not use euphemism in her works as in the "Why did Baby die?" poem [2]. In this poem, she did depict words such as "die", "death" "sigh" or "cry" to express her emotions on the death topic. Although she did not soften the situations with euphemism, she led the infant to the better for the next life. The focus of her poems is as much on the sorrow of those left living.

In the Victorian period, the relative frequency of child and infant death meant that there was more extensive consolation literature about children. Infant death was common but not treated as commonplace. In her 1872 book of lullaby's and rhymes for children, Sing-Song: A Nursery Rhyme Book, Christina $G$ Rossetti included seven poems about infant death. [3]

From the view of the models of word recognition and the role of semantic representations, we cannot explain why Rossetti's poems became popular even though she did not use any euphemism for writing death as an expression of religious hope. That is reason why we apply the Chafe's six semantic configurations to know how Rossetti's poems simply were learnt by hearts by generation to generation despite the fact her poems are likened as unforced expressions of her mind and religious poems.

\section{Christina Rossetti, Echo and the Thought of Death}

Christina Rossetti (1830-1894) was born in London, the United Kingdom in an Italian four - child family. Her father and brother were poets. Her first poems were published in 1842 by the private press of her family. In 1850 , seven of her poems, under the pseudonym Ellen Alleyne, were printed in the Pre-Raphaelite journal The Germ with her brother, William Michael, and his friends. She was also good at ballads and religious lyrics. That is the reason why her poems are marked by symbolism and intense feeling. Goblin Market and Other Poems, published in 1862, was one of her best works with a significant voice in Victorian poetry. The Prince's Progress and Other Poems (1986), and Sing-Song (1972) came next as the collections of verses for children. By the year of 1880 s, her social life was restricted by a thyroid disorder. The illness restricted her social life, but she does not give up her writing poems. She died in London on December 29, 1894 because of cancer. William Michael, her brother, edited her collection of works and published in 1979.

'Echo' is one of her best works for its imagery, symbolism and themes. She used some of imagery view such as eyes, door, gateway to call her lover back. With the symbols such as water, stream, and tears, she described her brimful of love. She wanted to express the theme "longing" throughout her tone of poem [7]. This poem recalls readers the regret for her lost love 'that has been made impossible by Rossetti's decision to dedicate herself to faith' [5]. Her voice in the poem is likened as her dreams of her love and wishes to be endured in Paradise.

One very special thing about Rossetti was that she was believed to pursue the thought of death throughout her life. Many of her poems in the late of her life were composed on that topic, showing her concerns about afterlife. She wrote so many poems on such way so that many literature critics raise their doubts about her religious devotion. It seemed that she had no tone to reflect the existence of the world in her poems. She always expressed her best praise of God and hope to go to heaven.

\section{Chafe's Theoretical Concepts}

\subsection{States}

States is a term to describe the situation of the predicate of the sentence. Let us examine the following examples as in [2: 98]:

Example 1:

1a. The wood is dry.

1b. The rope is tight.

1c. The dish is broken.

1d. The elephant is dead.

The predicates in sentences from (a) to (d) in example (1) such as is dry, is tight, is broken, is dead are described the conditions or the state of the noun the wood, the rope, the dish and the elephant. In other words, we can say these predicates are specifying the states of the nouns.

Chafe also suggested the way to test whether a predicate of a sentence is state or nonstate by answering the questions: "What happened?", "What's happening?" etc. Hence, the sentences in example (2) below are nonstate because each of 
them is an event and can be the answer to such a question like "What happened?" or "What's happening?"

Example 2:

2a. The wood dried.

$2 \mathrm{~b}$. The rope tightened.

2c. The dish broke.

2d. The elephant died. [2: 98]

\subsection{Processes, Actions and Ambient}

The nonstate sentences are quite different from one another. Let us examine more sentences in example (3) and (4) as in [2: 98]:

Example 3:

3a. Michael ran.

3b. The men laughed.

3c. Harriet sang.

$3 \mathrm{~d}$. The tiger pounced.

Example 4:

4a. Michael dried the wood.

$4 \mathrm{~b}$. The men tightened the rope.

4c. Harriet broke the dish.

$4 \mathrm{~d}$. The tiger killed the elephant.

The predicates in example (2) are dealing with the processes when their subjects changed their own states or conditions, so the predicates in example (2) have specified the processes. Because the subjects in these sentences also involved the relations with the predicate, we name the subjects (the nouns the wood, the rope, the dish and the elephant) the patient of their verbs. In the sentences in example (3), the predicates are different from the ones in example (1) and (2). They do not deal with a state or a change of its condition or state. They are something which a subject does. The general rule for recognizing the predicate which an action is to ask the question "What did the noun do?" For example: we can ask: "What did Michael do?" The answer is Michael ran (an action) but not Michael died (a process). By that way, we can say that the noun in the action sentences in example (3) cannot be the patient of its predicate. The sentences in example (4) are some kinds of both process and action. In other words, the states in example (1) and processes in example (2) are accompanied by patients, while the actions in example (4) by agents. Now, let us explore the sentences in example (4) to see how the predicate of these sentences involved both a process and an action on it.

As a process it involves a change in the condition of a noun, its patient. As an action it expresses what someone, its agent, does. The agent is still someone who does something, but in (4) the agent does it to (or sometimes with) something, the patient of a process [2: 100]:

\section{What did Harriet do?}

She broke the dish.

What happened to the dish?

Harriet broke it.

To sum up, the verb of the sentence can be a state, a process, an action or both a process and action verb. The type of the verbs is accompanied by a patient, an agent or both patient and agent with it. Besides the four kinds of the verbs or predicates, we also have the sentences having no "thing", but a predication like the following sentences

Example 5:

5a. It's hot.

5 b. It's late.

5c. It's Tuesday.

Chafe has named these kinds of predicates an ambient. The subject 'it' reflects nothing but the semantic structure' [2].

\subsection{Semantic Configurations}

From the observations of the combination between the verb and patient, agent, patient and/or agent, Chafe had created the six sematic configurations [2: 104] as follows:

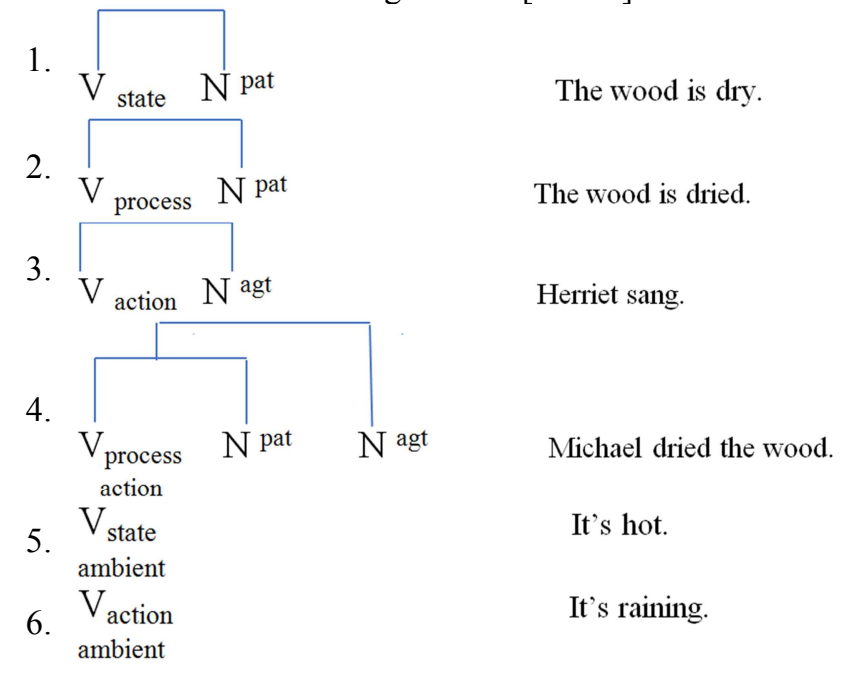

\section{Investigation Procedures}

Firstly, we check whether Chafe's six semantic figurations can work with all kind of sentences or not in the poem Echo, written by Christina Rossetti. 'Echo' captured the pain of losing a loved one and the longing to feel their presence in any form. (See Appendix) With this poem, we check the 'special sentences' in the poem with semantic structure rules suggested by Chafe.

Secondly, we modify the model to best interpret the meaning of the semantic structures. A sketch of the semantic structures is drawn to a sentence or group of sentences (that are similar in form) to demonstrate its semantic figurations.

Lastly, we use Chafe's theory as the referent to modify the semantic structures for the discussions and suggestions for better understanding the content of the poem.

\section{Results and Discussion}

\subsection{Semantic Configuration for an Imperative Mode to Add to the Supernatural Tone of the Poem}

Echo is the poem of 'echoes and repetition' that functions as a key of it. There are eighteen lines in the poem which are structurally arranged in a very special way to create echoes, first emitted and then bounced back over time to time. Each time the echo sounds it conveys the wishes of the writer. To 
analyze the semantic structures of the poem, we divided its eighteen lines into three verses to investigate each of the semantic configurations of it.

Let us examine the first verse in the poem. The verb come is used and repeated four times in the first verse and closing line of the verse starting with the sound 'o'.

(1a) Come to me in the silence of the night;

(1b) Come in the speaking silence of a dream;

(1c) Come with soft rounded cheeks and eyes as bright as sunlight on a stream;

(1d) Come back in tears;

O memory, hope, love of finished years.

If we just analyze the surface of the semantic structure of the lines in verse ( $1 \mathrm{a}-\mathrm{d})$, we see only model $V_{\text {ambient action }}$ to all lines, but the second pronoun "you" is omitted.

Therefore, the semantic configuration for this verse should be demonstrated as follows:

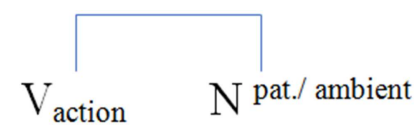

(1a) Come to me in the silence of the night;

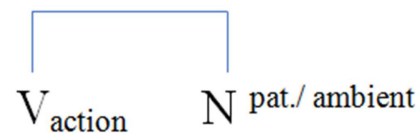

(1b) Come in the speaking silence of a dream;

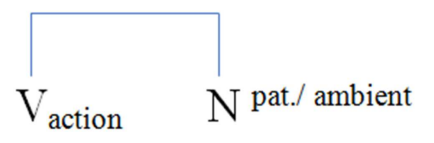

(1c) Come with soft rounded cheeks and eyes as bright as sunlight on a stream;

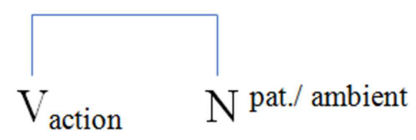

(1d) Come back in tears,

With the repeated patient, the language used in the first verse gets the readers to be moving and touching. The successful of using unnatural semantic structures "Action, ambient and patient model" in semantic configuration for an imperative mode to create a 'supernatural meaning' beyond its natural meaning. Without the configurations of meanings, we cannot know how words linked together to express of the writer's emotions with respect to her beloved one.

\subsection{The Relation of Noun to Verb and a Complex Model in Semantic Structure to Express a Dream}

In Chafe's theory, a general picture of semantic structure is related to the semantic configuration, in which the central verb are accompanied with one or more than one noun [2]. However, for the second verse of the poem "Echo", we cannot find the semantic structure with verb - noun relation. We only recognize verb-noun relation when we consider verbs, nouns in relations to the agent, patient and others. For example, in (2a) and (2b):

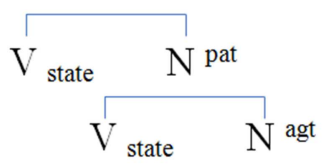

(2a) Whose wakening should have been in Paradise,

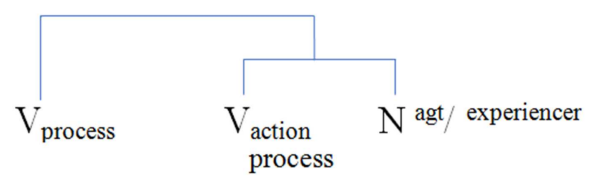

(2b) Where souls brimful of love abide and meet;

There are two verbs abide and meet which are accompanied with the noun phrase Souls brimful of love. Although Souls brimful of love are the triggers of an action, the meaning of abide is not someone did something. Verbnoun relation may belong to a mental process rather than an action. Therefore, the relation can be defined as a process or the noun accompanied as an experiencer. This relation is the way Christina Rossetti used to continue her sentimental and her sorrowful mode from the first verse. By moving from "state Verb with patient Noun" to "process Verb with experiencer Noun", she dreamed that their passing, their loved one is worthy of Heaven ('Paradise').

\subsection{Rolling "Agent" to "Patient" with the Inflection of Verb to Create the Stylistic Meaning for Echo Poem}

In the Echo poem, the most successful of it is that Christina Rossetti did not use generic, perfective, or past mode of semantic structures but progressive and anticipative mode. These kinds of inflectional verbs as thirsting, opening, or letting must be "bounded" to animate as in (3).

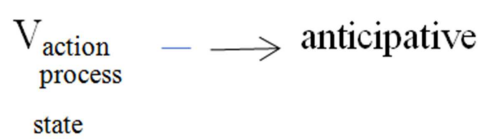

(3) Where thirsting longing eyes /watch the slow door / that opening, letting in, lets out no more.

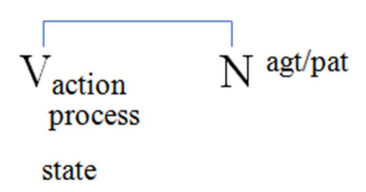

(4) Yet come to me in dreams, that I may live my very life again though cold in death: come back to me in dreams, that I may give / Pulse for pulse, breath for breath: Speak low, lean low /As long ago, my love, how long ago.

From (3) and (4), we can conclude that the hearer must have recognized the unique noun as a human being and "bounded" to the its meaning.

$$
\left[\begin{array}{l}
\text { Human } \\
\text { Bounded }
\end{array}\right]-\longrightarrow \text { Unique }
$$


In lines (3) and (4) of the final verse, the author of the poem yearned for her loved one to appear so that in dreams she can feel that he or she is still alive. In other words, she simply wanted to be healed her feeling with comfortable memory of her beloved one.

\section{Conclusion}

The investigation of Chafe's six semantic configurations through Rossetti's poem "Echo" has given a clear-cut picture of semantic structures. From the semantic configuration analysis of the poem, we can see that the poet has placed unusual importance and stress on afterlife through the breaking semantic configurations by mixing up agent, patient and experiencer in even a single sentence or imperative mode. With the change of semantic configurations, she has succeeded in her dual life style: one the current existence and the other one for death wish. She wrote Echo for her beloved longing person who had passed away from her from 'various inner necessities which can never be easily identified' [9]. For the poem Echo, understanding the meanings of verb in Chafe's theory is not enough; therefore, the best way is to analyze the nouns that accompany it. Obviously, the semantic structures are very helpful in better understanding the meaning of a poem or a literature work, especially for the supernatural works like Christina Rossetti's poems. This application may take effects for the other works in her life when she was 'at home in the dream house' to write 'the Dead City' when she was only sixteen [9: 9]. Because the application of Chafe's theory to discourse level is yet to determine, we suggest the six configurations should be taken into accounts in analyzing literature works to help students or readers to build their own complete conceptual structures before scanning words for meaning, especially stylistic meaning.

\section{Appendix}

Echo [6]

by Christina Rossetti

Come to me in the silence of the night;

Come in the speaking silence of a dream;

Come with soft rounded cheeks and eyes as bright

As sunlight on a stream;

Come back in tears,

O memory, hope, love of finished years.

O dream how sweet, too sweet, too bitter sweet,
Whose wakening should have been in Paradise, Where souls brimful of love abide and meet;

Where thirsting longing eyes

Watch the slow door

That opening, letting in, lets out no more.

Yet come to me in dreams, that I may live

My very life again though cold in death:

Come back to me in dreams, that I may give

Pulse for pulse, breath for breath:

Speak low, lean low

As long ago, my love, how long ago.

\section{References}

[1] Anderson, S. E., Chiu, E., Huette, S., \& Spivey, M. J. (2011). On the temporal dynamics of language-mediated vision and vision-mediated language. Acta Psychologica, 137 (2), 181189. https://doi.org/https://doi.org/10.1016/j.actpsy.2010.09.008.

[2] Chafe, W. L. (1970). Meaning and the Structure of Language. London/ Chicago: University of Chicago Press.

[3] Challis, D. (2016). Memento mori: grief, remembering, and living. The Lancet Psychiatry, 3 (3), 210-212. https://doi.org/https://doi.org/10.1016/S2215-0366(16) 000602.

[4] Chandler, D. (2002). Semiotics: The Basics. London: Routledge.

[5] CIE Literature. (n.d.). Echo. Retrieved March 2, 2018, from http://www.cieliterature.com/1251/.

[6] Rossetti, C. (n.d.). Famous Death Poem. Retrieved December 20, 2017, from

https://www.familyfriendpoems.com/poem/echo-by-christinarossetti.

[7] Rossetti, C. (1979). The Complete Poems of Christina Rossettie. Poem Analysis. Los Angles: Louisiana State University Press.

[8] Sajin, S. M., \& Connine, C. M. (2014). Semantic richness: The role of semantic features in processing spoken words. Journal of Memory and Language, 70, 13-35. https://doi.org/https://doi.org/10.1016/j.jml.2013.09.006.

[9] Yang, O. J. (1992). A Study Of Christina Rossetti’s Poems On Death. UNiversity of North Texas. Retrieved from https://digital.library.unt.edu/ark:/67531/metadc501076/\#top.

[10] Zwitserlood, P. (1989). The locus of the effects of sententialsemantic context in spoken-word processing. Cognition, 32 (1), 25-64. https://doi.org/https://doi.org/10.1016/0010-0277 (89) 90013-9. 